\title{
Avel-lí Artís i Balaguer (1881-1954), narrador
}

\author{
Avel-lí Artís i Balaguer (1881-1954), narrator
}

\author{
ÓsCar Fernández Poza (UCM) \\ oskarfp20@hotmail.com \\ Recibido: marzo de 2015. Aceptado: mayo de 2015.
}

\begin{abstract}
Resumen: En este artículo presento una faceta del editor, impresor y comediógrafo catalán Avel-lí Artís i Balaguer que no es mencionada dentro de las diferentes historias y monografías de literatura catalana, la de narrador. Se ordena el corpus de cuentos que hasta la fecha he localizado, publicados en diferentes revistas de la primera mitad del siglo XX, tanto en Cataluña como en el exilio.
\end{abstract}

Palabras clave: Literatura catalana contemporánea, Avel·lí Artís i Balaguer, cuento, costumbrismo, crítica social, guerra civil, exilio.

\begin{abstract}
This article presents a facet of the editor, printer and comedy writer catalan Avel-lí Artís i Balaguer that is not mentioned in the different stories and case studies of Catalan literature, the narrator. Ordering the corpus of stories that have located so far published in different magazines in the first half of the twentieth century in Catalonia and in exile is ordered.
\end{abstract}

Keywords: Catalan Contemporany Literature, Avel·lí Artís i Balaguer, story, costoms, social criticism, civil war, exile.

\section{PERFIL DEL NARRADOR}

Avel-lí Artís i Balaguer (Vilafranca del Penedés 1881- México D. F. 1954) es conocido, en mayor medida, como impresor, editor y comediógrafo, pero, en mi acercamiento al autor, he constatado así mismo su producción como narrador, como autor de una serie de relatos, publicados en diversas revistas catalanas de la primera mitad del siglo veinte, tanto editadas en Cataluña como en el exilio americano. En correspondencia con su dramaturgia, en su faceta de narrador se encuentra a grandes rasgos entre las dos tendencias literarias que, entre el cambio de centurias y el primer tercio de siglo XX, en buena medida condu- 
jeron el avance y la consolidación de las letras catalanas contemporáneas, el Modernisme y el Noucentisme.

La faceta ahora mencionada no se documenta en las historias, diccionarios, monografías o artículos sobre literatura catalana consultados y que tratan acerca del mencionado ciclo literario o en particular sobre Avel-lí Artís Balaguer. En los volúmenes de Història de la literatura catalana dirigidos por J. Molas (1986, 1987) o en la Literatura catalana contemporània de J. Fuster (1972) se le menciona fundamentalmente en su faceta de comediógrafo, como uno de los cultivadores por excelencia del género de la comedia ciudadana de principios de siglo. En el primer caso, esto lo podemos ver en los dos capítulos sobre teatro firmados por E. Gallen, en los volúmenes octavo y noveno de la mencionada Història de la literatura catalana (1986: 379-448; 1987: 413-462). Respecto de la segunda fuente (Fuster 1972: 298, 300, 303, 327), a su labor como hombre de teatro y director de La Nostra Revista en México — sólo posteriormente La Nova Revista (sic. Fuster 1972: 327) que dirigiría su hijo Avel-lí Artís-Gener-, solo añade como prosista su puntual aportación Adrià Gual i la seva obra (1944), en directa relación con su producción esencial, la teatral. Las referencias existentes en los diccionarios consultados -Diccionari de la literatura catalana bajo la dirección de J. Molas (1979: 56-57), Nou diccionari 62 de la literatura catalana dirigida por E. Bou (2000: 52) y — solo le señalan en su labor como comediógrafo, editor y periodista. En el caso del Diccionari d'escriptors en llengua catalana de R. Sargatal (1998) no se le menciona.

En cuanto a las monografías y artículos existentes, debo referirme a aquellos textos que hablan estrictamente de Avel-lí Artís Balaguer o a los que se centran en la narrativa breve como género, coincidiendo con las etapas de su producción literaria. En los títulos concernientes al cuento, solo existe una única referencia acerca de él como escritor que lo cultivara, dentro de una antología de textos de autores catalanes sobre la primera Navidad que viven en el exilio, El Nadal que no vam a tornar a casa de Quim Torra i Pla (2009). En las demás antologías consultadas sobre el cuento durante el Modernisme, el Noucentisme y el periodo posterior al desastre de 1936, no se halla noticia alguna. A saber, los dos volúmenes de la Antologia de contes catalans de J. Molas (1987, 1991), Antologia de contes modernistes de J. Castellanos (1987), El conte de 1911 a 1939 de M. Campillo (1983), y El conte des de 1939 de E. Centelles (1981). En la recopilación Contes de guerra i revolució (I, II) de M. Campillo (1982) tampoco se da ninguna referencia a Avel-lí Artís Balaguer ni al texto que escribió en esta época y recuperado en estas páginas, «Fi d'any. El retrò dels canons a la reraguarda», mientras que se citan y se antologan (Campillo I 1982: 89-94; 173-178) dos relatos de Avel-lí Artís-Gener, Tisner, hijo mayor del autor aquí atendido.

Por su parte, en las páginas puntualmente dedicadas al escritor vilafranquino, se puede decir que no hay referencia a su faceta como narrador, con una única excepción indicada en último párrafo de este punto. En este sentido, cabe mencionar varias voces autorizadas sobre su figura, por pertenecer a la familia o por ser amigos o conocidos suyos. En cuanto a la información procedente del medio familiar, contamos en estos momentos con dos referencias de peso pero 
con nulo resultado: la autobiografía en cuatro volúmenes de A. Artís-Gener, Viure i veure (1989-1996; vid. también 1977) y el estudio y edición de cuatro de sus obras, publicado recientemente por su bisnieta D. Corominas i Calders, Avel-lí Artís i Balaguer i Barcelona: vida i obra (2014). Tampoco son útiles los títulos debidos a los amigos o conocidos, entre los que cabe mencionar los siguientes textos: el libro De l'exili a Mèxic de A. Bladé i Desumvila (1993), donde se recogen una serie de conversaciones que su autor tuvo con Avel-lí Artís i Balaguer y que previamente se publicaron en la revista Xaloc; otro tanto el artículo de este mismo autor «Avelí Artís. Impressor i comediògraf» (1964) y asimismo el libro Els exiliats catalans a Mèxic de V. Riera Llorca (1994).

También se puede aludir a los artículos que aparecieron tras su muerte, en diversas publicaciones tanto del exilio como desde Cataluña, donde no se menciona esta vertiente de su obra. Por ejemplo, los publicados en La Nova Revista, dirigida por Avel-lí Artís-Gener, que se centran en su figura como nexo entre los exiliados catalanes en tierras americanas y Cataluña. Véase «A la memòria d'Avelí Artís» de P. Foix (1955) o el artículo «Els anys de La Mainada» de R. Tasis (1955).

Existen dos referencias al respecto sobre la evidencia de una novela del autor. Una es en Tísner, l'escenògraf de J. Romaguera i Ramió (1995: 72), donde se hace referencia a que antes de casarse en primeras nupcias con Maria Gener i Buixens (Vendrell, 1887-Barcelona, 1927), quien será la madre de todos sus hijos, sufrió un desengaño amoroso, y una vez superado, escribió una novela corta que jamás se editó «i que esquinçà ja morta la desitjada». Y la otra es en L'assaig de la vida de Plàcid Vidal (1934: 217-218), quien sitúa su escritura en torno a 1906 además de narrarnos su argumento. Si comparamos el argumento resumido por Plàcid Vidal con el finalmente desarrollado en Ninots de carn (1911), se evidencia una modificación en su escritura. Solo aventuraré que como narrador, el autor tratará sobre infortunios de pareja; en la versión que nos da Plàcid Vidal su causa es la enfermedad de la mujer, y en la versión definitiva, dichas desgracias se deben al control del marido sobre su pareja y el intento de la protagonista para escapar del mismo.

\section{CORPUS NARRATIVO}

El corpus que presento está compuesto de once cuentos y una novela corta.

Cuentos:

— «La Siò», Catalunya Artística, 56, (4-VII-1901), pp. 340-342.

— «El bohemi», Catalunya Artística, 112, (7-VIII-1902), pp. 513-516.

— «El palau del esclavatge», Joventut, 253, (15-XII-1904), pp. 816-818.

— «Nadal», Joventut, 308, (4-I-1906), p. 8.

— «La festa de les minyones», Joventut, 318, (15-III-1906), pp. 164-165. 
— «Us anyoro, vehinas», Almanac de l'Esquella de la Torratxa, 1910, pp. 90-91.

— [sin título], Almanac de l'Esquella de la Torratxa, 1912, p. 50.

— «Martínes, editor», Mirador, 9, (21-III-1929), p. 4

— «Fi d'any. El retrò dels canons a la reraguarda», Meridià, 52 (7-I-1939), pp. 2, 5 .

— «Aquest Nadal a casa nostra», El Poble Català (19-I-1939)1.

— «La reserva», La Nostra Revista, 20, (agosto 1947), pp. 313-315

Novela Corta:

— «Ninots de Carn», Almanac de l'Esquella de la Torratxa, 1911, pp. 38-48.

Como se puede ver en el corpus presentado y atendiendo a la cronología de publicación, la producción de Avel-lí Artís Balaguer como narrador se ordena en tres periodos:

- el primero abarcaría sus años de formación como escritor (1901-1906), donde se ven los primeros indicios literarios que posteriormente se plasmarán en su dramaturgia.

- el segundo coincide con las primeras obras dramáticas (1910-1912).

- el tercero, coincidente con su éxito teatral y su mayor dedicación a la actividad editorial, comprende sus últimas narraciones (1929-1947).

Los cortes temporales que separan dichos periodos, si se atiende a la biografía del autor, tal vez se puedan explicar por diversas causas. El límite del primer período cabe argumentarlo por el comienzo de su carrera como comediógrafo, a finales de la primera década del siglo, con su estreno en los escenarios barceloneses en 1909 y, a la vez, por su actividad en la prensa. En 1906, además, tras diversos proyectos en revistas satíricas desde Palla Nova (1904) a Marramau (1906), entra a formar parte de la plantilla de El Poble Català, como corrector de pruebas. Desde las páginas de este periódico, junto con Plàcid Vidal, Joan Puig i Ferreter y Antòn Isern, lanza una campaña, como modernista y hombre de teatro, para que se levante una estatua en honor del dramaturgo noruego Henrik Ibsen.

El segundo salto es debido a su éxito como comediógrafo y a su citada labor profesional como colaborador en diversas revistas, como El Teatre Català (1912-1917), La Mainada (1921-1923), o por la apertura de la Llibreria Renaximent (1929). De la misma forma se puede explicar la dilación de las narraciones en el tercer periodo, ya que cabe decir que es un tiempo convulso, tanto

${ }^{1}$ El editor de la antología donde aparece publicado este cuento, nos da la información de que fue escrito en Saltillo, Estado de Coahuila, en diciembre de 1939. 
colectivamente como en lo personal, desde la preguerra al exilio. A este periodo se deben también sus últimas aportaciones a la escena catalana, y asimismo sus actividades junto a otros escritores catalanes contra el alzamiento por parte del ejército y, por último, el exilio, primero en Francia y posteriormente en México.

\section{REVISTAS Y RELATOS}

En este apartado se hará una breve presentación de las revistas donde aparecen publicadas sus narraciones. Se puede decir que todas ellas fueron editadas en Cataluña, menos dos que aparecerán en México.

Catalunya Artística (1900-1905) es una revista semanal sobre literatura y arte publicada en Barcelona. Estuvo dirigida por Joaquim Ayné Rabell y contaba entre sus colaboradores con Pompeu Crehuet, Eduardo Marquina y Apeles Mestres. La publicación se mueve entre presupuestos de índole modernista. Aquí aparecieron sus dos primeros relatos.

Joventut (1900-1906) es una revista que manifestaba, como aparece en el artículo presentación de su primer número, su fidelidad a las Bases de Manresa «i de fe en el progrés intel-lectual i material de Catalunya» (Torrent 1966: 344). Fue editada por Fidel Giró. Dirigida por Lluís Via, tuvo firmas como la de Salvador Vilaregut, Emili Tintorer, Alexandre de Riquer, Pompeu Gener. También publica algunos «Suplements Artístichs» en papel couché, muy bien ilustrados, como indica J. Torrents (1966: 347), «que van obtenir una magnífica rebuda del públic». Como la mayoría de las revistas, de este periodo, Joventut publica un número anual -en otros era nombrado Calendari o Almanac - que recibía el nombre de «Número de Cap d'Any», con numerosas ilustraciones y colaboraciones escogidas. La publicación responde a un Modernisme que los comentaristas de la revista aprecian como ecléctico. En sus páginas se publicaron tres de los relatos.

Almanac de l'Esquella de la Torratxa (1889-1932) es la publicación anual de la revista del mismo nombre. Semanario humorístico republicano, de gran incidencia política e influencia popular. Colaboran casi todos los caricaturistas, ilustradores y humoristas catalanes de cuatro generaciones. Dirigida desde su fundación hasta 1907 por Josep Roca i Roca, tuvo después la influencia editorial de Màrius Aguilar, Prudenci Bertrana, Francesc Madrid, Lluís Capdevila, Ramon Vinyes y Pere Calders, entre otros. Aparecen firmas como Santiago Rusiñol, Gabriel Alomar, Ramon Reventós, J. F. Guibernau, Josep Burgas y Francesc Curet. Entre los dibujantes figuran Apel-les Mestres, Isidre Nonell, Feliu Elias (Apa), Jaume Passarell, Ricard Opisso y Josep Costa (Picarol), escenógrafo de alguno de los estrenos de Avel-lí Artís Balaguer. En este caso y dado su largo recorrido cronológico, revista y almanaque pasaron por diversas etapas y adscripciones estéticas que vienen a coincidir con el perfil de sus responsables y colaboradores. Dado que los tres textos de Avel-lí Artís Balaguer se incluyeron entre 1910 y 1912, anótese que se publican en una etapa de corte modernist $a$ en lo que se refiere a las directrices de la publicación.

Mirador (1929-1937), semanario de literatura, arte y política, fue fundada en Barcelona por Amadeu Hurtado y dirigida por Manuel Brunet y Just Cabot. Tuvo 
las colaboraciones de Josep M. de Sagarra, Josep M. Planas, Andreu A. Artís, Jaume Passarell, C. A. Jordana, Sebastià Gasch, Joan Teixidor, Martí de Riquer, Rafael Tasis, Rossend Llates, etc. En la publicación puede reconocerse tanto un fondo de regusto noucentista como evidenciar los signos de modernidad propios de la cronología más adelantada del periodo de entreguerras. Durante la Guerra Civil fue requisada por el PSUC, y estuvo dirigida por Artur Perucho hasta 1938, que fue sustituida por Meridià. Aquí se publicó un único texto del autor.

Meridià (1938-1939), semanario de literatura, arte y política, editado en Barcelona y subtitulado «Tribuna del Front Intel-lectual Antifeixista», hará por mantener el prestigio de Mirador. Mantiene un eclecticismo en la elección de los colaboradores literarios. Tuvo como director a Antoni Fuster i Valldeperes y Manuel Valldeperes, la redacción estaba formada por Sebastià Gasch, Domènec Guansé, Lluís Montanyà, Joan Oliver, J. Roure-Torrent y Manuel Serra i Moret. Entre sus colaboradores aparecen la mayoría de los escritores y de caricaturistas catalanes del momento. La revista acoge un texto de Avel-lí Artís i Balaguer.

El Poble Català (1939-1940) fue una de las primeras publicaciones que aparecieron en el exilio. Primero se publica en París y posteriormente en México (1941-1947, 1948-1950, 1951-1953) como El Poble Català. El Portanveu de la Comunitat Catalana de Mèxic. En su época parisina fue publicado por Rafael Tasis i Marca y Jaume Miravitlles i Navarra. Su ideario es nacionalista.

La Nostra Revista (1946-1954), publicación cultural y política recogiendo los idearios de Esquerra Republicana y Acció Catalana, fue fundada y dirigida en México por nuestro autor. Vicenç Riera i Llorca fue redactor y secretario y, los últimos años, Joan Rossinyol actuó como secretario. Fue ilustrada por artistas como Francesc Domingo, Emili Grau-Sala, Gausachs, Carles Fontseré y Avel-lí Artís-Gener. Fue una de las tribunas más importantes del exilio catalán. Aparecen colaboraciones como las de Mercè Rodoreda, Ventura Gassol, Joan Fuster, Antoni Rovira i Virgili, Josep Carner, Ferran Canyameres, Pere Bosch i Gimpera, Josep Ferrater Móra, Pere Foix, Manuel Serra i Moret, Pere Calders, Avel-lí Artís-Gener, Rafael Tasis, Ramon Vinyes, etc. Aquí apareció la última aportación narrativa de Avel-lí Artís Balaguer hasta ahora localizada.

\section{ANÁLISIS DE LOS RELATOS}

Los textos narrativos de Avel-lí Artís Balaguer, correspondientes a las dos primeras etapas antes establecidas, están marcados por el Modernisme. No obstante, sin atender expresamente a la actitud nostálgica ni seguidamente a «la voluntat de fixar uns estereotipus socials», siguiendo en cierta medida la línea de Santiago Rusiñol «en capgirar la nostàlgia i l'humor costumistes per la sàtira, la crítica o la caricatura» (Castellanos 1987: 28); ni tampoco a una tercera vía mencionada por J. Castellanos (1987: 28), la que recupera «la vella funció ideològica amb el retorn a les concepcions tradicionals d'identificació de la col-lectivitat nacional amb unes formes de vida determinades, aspecte que obria camí, (...) al costumisme més estereotipat, rural o urbà». 
Son bocetos costumbristas, que se plasmarán posteriormente en su dramaturgia, y que tal vez empleará como ejercicio para sus elaboradas y minuciosas descripciones de espacios urbanos de orden interior, tal y como aparecen en las acotaciones de sus obras dramáticas.

La temática presentada en los textos narrativos de sus dos primeras etapas es doble:

- La más explícitamente costumbrista, entroncada con la tradición del «costumisme barceloní» desde Robert Robert a Emili Vilanova: «La Sió» (1901), «El Bohemi» (1902), «La festa de les minyones» (1906), «Us anyoro, vehines» (1910) o el que no tiene título (1912).

- La de alcance social, pero sin desatender del todo el plano costumbrista: «El Palau del esclavatge» (1904), «Nadal» (1906) y «Els mobles al carrer» (1906), más la novela corta Ninots de carn al abordar la crisis de los valores de género en la pareja tradicionalmente constituida.

Las narraciones parten de una anécdota de la vida cotidiana, como puede ser una boda, comer una fruta, el desahucio de una familia, etc., pero siempre hay algún matiz que va más allá de lo meramente costumbrista. Estas anécdotas se dan principalmente en el medio urbano de la gran ciudad, Barcelona, aunque en ocasiones no se mencione ningún espacio suyo reconocible. Por el contrario, son excepción los cuentos «La Sió» y «La festa de les minyones», donde se remite a unos espacios concretos de la urbe. No obstante, en dos de los cuentos el narrador sitúa la acción en un ámbito cercano a lo periféricamente urbano, en uno en una población costera, «El palau del esclavatge», y en el otro en la montaña, «El bohemi», texto que en ese medio y además acumula mayor número de motivos de filiación modernista.

En su primer texto, «La Sió», argumentado a partir de la anécdota de una boda, se recrea un mundo compartido entre el narrador y el personaje femenino que da título a la narración. Va de lo general, de la geografía urbana del barrio («carrer Mitjá de Sant Pere, (...) l'iglesia d'aquell Apóstol») a lo particular, el balcón del piso de la Sió; presentado este último como un espacio bucólico donde se refleja su estado anímico — de uno inicial alegre y primaveral, a otro sombrío y triste tras no celebrarse la boda—, frente al balcón del narrador, que desde un principio es melancólico. La narración concluye con un «raig de sol», signo de esperanza, de un amor incipiente. A diferencia del perfil de estos dos protagonistas, los distintos personajes vecinos del barrio, todavía nos recuerdan a los del sainete costumbrista, sin matices psicológicos.

Por su parte, el pequeño relato sin título o «La festa de les minyones» son narraciones más claramente costumbristas; descriptivas de un momento de la vida cotidiana, hasta el punto que el primero de ambos títulos hace gala de una factura pictórica que casi lo convierte en un lienzo. Aunque, por su parte, «Us anyoro, vehinas» también se puede encuadrar en la mencionada línea costumbrista, hay una clara diferencia con las otras dos narraciones, en particular al encarar el tratamiento del personaje femenino. En este caso, es 
más sensual, casi erótico, opción reflejada en la descripción de una de las vecinas:

Y ara, ¿ahónt heu antat, vehinas? Trobraréu, á la casa nova, qui us veneri, qui us estimi ab aquella estimació tant meva que sab desitjar y respectar, que sab voler y doler, que sab mirar, ab lluhissor als ulls, las curvas dels brassos, las turgencias dels pits, la rojor dels llabis, la carn rosada de la pitrera, y allunyar els pensaments impúdichs, com en santa contemplació d'una obra d'art? (Artís i Balaguer 1910: 91).

Otros cuentos, con una ligera temática social, añaden la crítica a diferentes asuntos que en aquellos momentos eran candentes en la sociedad catalana. En «El palau del esclavatge», sitúa la acción en una población costera; los temas que aparecen van desde la preocupación por la contaminación al fracaso económico de una parte de la pequeña burguesía que había vuelto de hacer las américas y al anticlericalismo. Sus personajes representan colectivos sociales, exceptuando al dueño de la fábrica, aunque no se incide en sus psicologías. En cambio, la fábrica aparece personificada, es la verdadera protagonista del relato, la cual pasa de motor económico del pueblo a convento de monjas y a recinto militar, como indicio de los cambios que impone el paso del tiempo sobre la sociedad.

En «Nadal» $\mathrm{y}$ «Els mobles al carrer» — de nuevo a partir de una anécdota de la vida cotidiana con incidencia crítica y social- el desahucio de unas familias le permite al autor recrear ambientes urbanos y encuadres costumbristas. Se hace una crítica a la especulación urbanística que está sufriendo Barcelona; crítica aún velada si se compara con la que posteriormente, ya a finales de la década de los veinte, desarrollará como tema para una de sus obras dramáticas, Els cincs sentits (1927). En esta dirección y reincidiendo sobre este tema, cuéntese también con el diálogo de 1914, recuperado y editado por D. Corominas i Calders (2014: 66-77).

Como se ha notado previamente, la novela corta Ninots de carn es una narración acerca de las relaciones de pareja, protagonizada por Arcadi y Felissa. El autor recrea un mundo de sentimientos encontrados en el espacio urbano, desde la perspectiva del narrador; el diálogo que hay es casi inexistente, rasgo que resulta hasta sorprendente tanto si se compara con algunos de los otros relatos como si se piensa en el comediógrafo que ya escribe para la escena. Tal vez, atendiendo a la economía de diálogos y a su situación precisa en la novelita, se pudiera pensar que, quien está cobrando valor como comediógrafo, también quisiera probarse a sí mismo como narrador.

Avel-lí Artís i Balaguer en esta novela sigue más de lejos en la línea costumbrista de sus narraciones pero hay pinceladas de sentimentalismo que abundan en el perfil de los personajes, aunque, en esa dirección, no caerá en las características extremas de la novela más sentimentalista. Incluso se puede apreciar que, estructuralmente, el relato avanza mediante secuencias focalizadas y de orden paralelo acerca de los pensamientos y cavilaciones de la pareja protagonista. 
De acuerdo con su relación, Arcadi y Felissa no están en el mismo nivel a lo largo de la historia. Es decir, en ningún momento hay una armonía entre los dos personajes. Al principio Arcadi se encuentra tranquilo, sereno, seguro de la decisión que ha tomado, mientras que Felissa, por lo contrario, se muestra nerviosa, intranquila. Pero ya desde los primeros momentos esto va cambiando, hasta llegar al final de la narración donde Felissa se muestra firme mientras que Arcadi está desesperado, inestable, hasta el punto de pensar en el suicidio, porque aunque no ha querido nunca a su mujer, comprende que ha perdido algo.

En esta narración hay un tema interesante para la época, el de la creciente libertad de la mujer y el alcance de la igualdad tanto en derechos como en la forma de actuar por parte del hombre y la mujer. Esta no tiene la libertad a favor de una vida propia, tiene que estar bajo la protección del hombre, incluso debiera moldearse a sus gustos como se muestra en esta novela. Pero la mujer se rebela y empieza a tomar sus decisiones, primero abandonando a su esposo y luego, poco a poco, tomando las riendas de su vida. Entiendo que este texto y a pesar de que las ilustraciones que lo acompañan nos instalan en el fin de siglo, de acuerdo con determinadas tomas de posición de la época hace por inaugurar una narrativa que ya en la frontera de los años veinte conformará argumentalmente textos de Carles Soldevila. En su producción teatral, el propio Avel-lí Artís Balaguer resolvería la cuestión con fórmulas más equilibradas, este es el caso de Isabel Cortés, vda. de Pujol (1928) y de La senyoreta porta el volant (1930).

Por último destaco una de las descripción que se hace de la protagonista, Felissa, que, como ocurría en el cuento «Us anyoro, vehinas», apunta un aire sensual a propósito de la figura femenina:

S'hi havia encegar pel seu aire de noia que encara anava de curt, ensenyant el contorneig de la cama esbelta, els cabells orlant d'or la seva cara blanca, de pell fina y delicada com un sedós lliri de Sant Antoni. Era ben hermosa ella, aleshores! Era ben hermosa aquella noia que perdé la gensor a mida que ell, impudic, la besava! (Artís i Balaguer 1910: 41).

En los tres últimos relatos rescatados hasta el presente se observa una evolución en la técnica y en la elaboración de los textos. Por su tratamiento, ya no se corresponden tan evidentemente con ejercicios que podemos considerar próximos o derivados del Modernisme. Me arriesgo a pensar que, por imposición de materia más personal e inmediata, como es la derivada de su profesión, de los bombardeos sufridos por Barcelona durante la guerra y de su propio exilio, rige un tratamiento más comprometido.

En «Martínez, editor» (1929), junto con un fondo todavía de ecos costumbristas, aparecen pequeños elementos biográficos que nos acercan a su labor como editor. Con el grado de objetividad que ello concede al narrador, se critica una forma de entender el negocio, la de vender lo máximo posible sin atender a la calidad del producto. Avel-lí Artís i Balaguer, como han reflejado A. Bladé i Desumvila (1993: 165), se convertirá en uno de los últimos representantes de un arte, el de la impresión «lligat a totes les glòries de l'espirit i a totes les pàgines, 
sense metàfora, més brillant de la cultura moderna». De este arte conocía el escritor todos los secretos, todos los requisitos y todo esto gracias a la época de aprendizaje que le tocó vivir, una época todavía poco industrializada y «quan un autèntic impressor podia fer, i feia, tot allò que li era consubstancial, des de compondre un prospecte a la mise en page acuradíssima, de la simple tècnica de la targeta al tiratge d'una enciclopèdia.» (Bladé i Desumvila: 165-166). Avel-lí Artís i Balaguer siempre ponía gran esmero en el cuidado de los textos impresos y, muchas veces, él mismo realizaba las labores más delicadas. Ese es el perfil de editor que llevará hasta su etapa mexicana.

«Fi d'any» (1939), texto mixto entre el cuento y el texto periodístico, de nuevo con tintes biográficos, es una crónica de guerra desde su propia ciudad. El narrador encuadra el dato dramático de los bombardeos y de sus consecuencias entre descripciones, retratos de tipos y diálogos que documentan la reutilización de sus antecedentes costumbristas, incluida una cierta moraleja.

En «Aquest nadal a casa nostra» (1939, ed. 1940), nos volvemos a encontrar con un texto híbrido, donde se confunden los límites del género del cuento con el texto periodístico, a la vez que se recupera el fondo de corte biográfico. Narra cómo han transcurrido esas fechas tan señaladas en esos primeros momentos de dudas y de miedos, y expresa su añoranza, no solo por sus seres queridos que se han quedado en Cataluña sino también por su tierra.

«La reserva» (1947), por su parte, es una narración que tiene como núcleo del relato el tema del exilio y todos los problemas que se derivan de él, la soledad, la añoranza de la propia tierra y de la familia que se abandona tras una situación complicada, etc. Es un cuento en el que cabría reconocer emociones y datos biográficos del autor, proyectados sobre la protagonista femenina, lanzada a la experiencia del camino del exilio, tanto del itinerario físico como del conflicto interno, vividos ambos por él mismo y por otros tantos exiliados. El relato comienza narrando la salida de la protagonista de Barcelona ante la inminente entrada de las tropas franquistas. Su viaje hacia el exilio supondrá el itinerario vital y real que Avel-lí Artís Balaguer y otros escritores catalanes tuvieron que realizar para escapar de la guerra y la probable represión por las tropas del general Franco. Téngase presente que, a través de la protagonista y narrando su travesía atlántica, se expresan las dudas que tendrían muchos de los exiliados ante la nueva situación que estaban viviendo, los miedos ante la llegada a una nueva tierra desconocida y extraña para ellos, las bajezas que tenían que hacer cometer para sobrevivir, robar, engañar... Todo ello, contando a su favor con un único valor, el del honor y pensemos que el autor, escribiendo acerca de todo ello ya a finales de los años cuarenta, está sintetizando narrativamente todo un ciclo vital de sí mismo y de su generación.

Sin ánimo de exagerar el valor del texto pero si apoyando su revalorización, considero que «La reserva» debiera figurar junto a otros textos que, merecidamente, se citan y estudian a la hora de valorar el documento y la literaturización del exilio como son algunos de Anna Murià o de C. J. Jordana. Y, así mismo, para acabar, destacaré que en los relatos de Avel-lí Artís Balaguer se encuentran indicios que se acogen a la estética y a las prácticas establecidas; no obstante, cabe también apreciar a su favor que no se queda en la mera reiteración de los 
clichés, apuntando a su factible evolución, como se puede comprobar en algunos de los textos que he presentado en el artículo, tal es el caso de Ninots de carn.

\section{BIBLIOGRAFÍA}

\subsection{Corpus}

Artís i Balaguer, A. (1901) «La Siò», Catalunya Artística 56 (4-VII-1901), pp. 340-342.

- (1902) «El bohemi», Catalunya Artística 112 (7-VIII-1902), pp. 513-516.

- (1904) «El palau del esclavatge», Joventut 253 (15-XII-1904), pp. 816-818.

— (1906a) «Nadal», Joventut 308 (4-I-1906), p. 8.

— (1906b) «La festa de les minyones», Joventut 318 (15-III-1906), pp. 164-165.

- (1910) «Us anyoro, vehinas», Almanac de l'Esquella de la Torratxa, pp. 90-91.

- (1911) «Ninots de Carn», Almanac de l'Esquella de la Torratxa, pp. 38-48.

- (1912) [sin título], Almanac de l'Esquella de la Torratxa, p. 50.

— (1929) «Martínes, editor», Mirador 9 (21-III-1929), p. 4.

- (1939) «Fi d'any. El retrò dels canons a la reraguarda», Meridià 52 (7-I-1939), pp. 2, 5 .

— (1947) «La reserva», La Nostra Revista 20, pp. 313-315.

\subsection{Estudios}

Artís-Gener, A. (1977) «Morts a l'exili. Avel-lí Artís i Balaguer», Avui (17 de abril), p. 4.

- (1989-1996) Viure i veure, Barcelona, Editorial Pòrtic, 4 vols.

Bladé i Desumvila, A. (1964) «Avelí Artís. Impressor i comediògraf», Serra d'Or, 1, pp. 47-48.

- (1993) De l'exili a Mèxic, Barcelona, Curial.

Bou, E (2000) Nou diccionari 62 de la literatura catalana, Barcelona, Edicions 62.

Campillo, M. (1982) «Pròleg» en Contes de guerra i revolució (I). Barcelona, Laia, pp. 9-471.

- (1983) «Estudi introductori» en El conte de 1911 a 1939. Barcelona, Edicions 62 , pp. 7-31. 
Castellanos, J. (1987) «Estudi introductori» en Antologia de contes modernistes. Barcelona, Edicions 62, pp. 5-40.

Centelles, E. (1981) «Estudi introductori» en El conte des de 1939. Barcelona, Edicions 62, pp. 5-27.

Coromines i Calders, D. (2014) Avel-lí Artís i Balaguer i Barcelona: vida $i$ obra, Barcelona, Ajuntament de Barcelona.

Foix, P. (1955) «A la memoria d'Avelí Artís», La Nova Revista 2, p. 50.

Fuster, J. (1972) Literatura catalana contemporánea, Barcelona, Curial.

Gallén, E. (1986) «El Teatre», Història de la Literatura Catalana. Vol. 8, Barcelona, Ariel, pp. 379-448.

- (1987) «El Teatre», Història de la Literatura Catalana. Vol. 9, Barcelona, Ariel, pp. 413-462.

Gran Enciclopedia Catalana: http://www.enciclopedia.cat/ (consulta: 22/03/2015)

Molas, J. (1979) Diccionari de la literatura catalana, Barcelona, Edicions 62.

- (1987, 1991) Antologia de contes catalans, Barcelona, Edions 62, 2 vols.

Riera Llorca, V. (1994) Els exiliats catalans a Mèxic, Barcelona, Curial.

Riquer, M. de + Comas, A. + Molas, J. (1986, 1987) Història de la Literatura Catalana, Barcelona, Ariel.

Romaguera i Ramió, J. (1995) Tísner l'escenògraf, Barcelona, Editorial Pòrtic, S. A.

Sargatal, R. (1998) Diccionari d'escriptors en llengua catalana, Barcelona, Edicions 62.

Tasis, R. (1955) «Els anys en La Mainada», La Nova Revista 1, pp. 11-14.

Torra i Pla, Q. (2009) El Nadal que no vam tornar a casa, Barcelona, A Contra Vent.

Torrent, J. + Tasis, R. (1966) Història de la Premsa Catalana. Barcelona, Bruguera, vol. I.

Vidal, P. (1934) L’assaig de la vida, Barcelona, Imp. Clarasó. 